
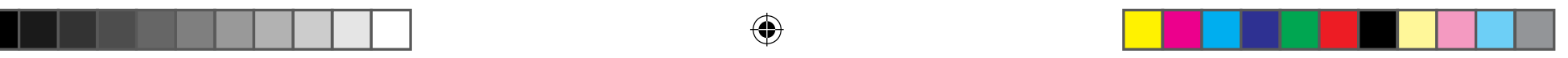

\title{
TAHAP PENERIMAAN GURU SEJARAH TERHADAP PENGGUNAAN APLIKA- SI MOBILE DALAM PEMBELAJARAN SUBJEK SEJARAH
}

\author{
MOHD SYAMSULFITRI MOHAMAD IDRIS* \\ KHAIRUL AZHAR MAT DAUD* \\ azhar.md@umk.edu.my
}

\begin{abstract}
Abstrak
Proses pengajaran dan pembelajaran dilihat menjadi semakin mencabar khususnya terhadap guruguru di sekolah. Penggunaan kaedah yang semakin maju dan moden perlu dipelajari oleh guru-guru agar pelajar tidak ketinggalan terutama dari segi pengajaran menggunakan kaedah yang lebih moden. Kajian ini adalah untuk melihat tahap penerimaan guru sejarah terhadap penggunaan aplikasi mobile dalam penyampaian subjek sejarah. Kajian ini memfokuskan kepada guru-guru matapelajaran sejarah di 15 buah sekolah menengah negeri Kelantan yang mana mewakili kawasan luar bandar dan bandar. Kaedah kuantitatif digunakan untuk melihat tahap keperluan guru terhadap penggunaan aplikasi mobile dalam penyampaian subjek sejarah. Hasil kajian telah direkodkan dan mendapati tahap penerimaan guru terhadap penyampaian subjek sejarah menggunakan medium pembelajaran menggunakan aplikasi mobile adalah tinggi.
\end{abstract}

Kata kunci: Penerimaan, Aplikasi Mobile

* Pelajar Pascasiswazah di Fakulti Teknologi Kreatif dan Warisan, Universiti Malaysia Kelantan, Malaysia

** Pensyarah Kanan di Fakulti Teknologi Kreatif dan Warisan, Universiti Malaysia Kelantan, Malaysia 


\begin{abstract}
In the 21st century, the learning process needs to be integrated with the latest information technology. The process of teaching and learning is very challenging. The integrating of advanced technologies in teaching process is very crucial and must be learned by teachers, so that students are not left behind in their learning. This study is to examine the level of acceptance and the level of needs to use mobile phone as a medium to teach historical subjects towards historical teachers. Data were collected by using quantitative method. Questionnaires have been distributed among historical teachers whose are teaching historical subject at 15 secondary schools in Kelantan. The schools involved are located in the rural and urban areas. Data have been analysis and the finding of the study have been recorded and found that the level of teacher acceptance and level of needs to use mobile phone as a medium to teach historical subject is high.
\end{abstract}

Keywords: Reception, Mobile Application

* Postgraduate student at Faculty of Creative Technology and Heritage, Universiti Malaysia Kelantan, Malaysia

** Senior Lecturer at Faculty of Creative Technology and Heritage, Universiti Malaysia Kelantan, Malaysia 


\subsection{Pengenalan}

Dalam pendidikan di Malaysia, subjek sejarah merupakan subjek yang penuh dengan bahan teori, konsep dan fakta yang mana menyebabkan pelajar perlu banyak membaca untuk memahami dan mengingati setiap maklumat kronologi yang terkandung dalam bahan bacaan tersebut. Seperti yang dinyatakan oleh Zuhara Aziz dan Nurliah Jair (2009), mata pelajaran sejarah mengandungi banyak idea yang abstrak serta konsep yang kadangkala sukar difahami. Konsep ini amat penting untuk mencorakkan daya pemikiran dan membentuk daya intelektual pelajar. Namun, pelajar tidak akan memahami sesuatu konsep jika tidak mengetahui maksud atau makna perkataan tertentu.

Pendidikan sejarah sebagai asas ilmu kemanusiaan dan kemasyarakatan telah lama diajar di sekolahsekolah di Malaysia. Pada tahun 1984, selepas pengenalan Kurikulum Bersepadu Sekolah Menengah (KBSM), mata pelajaran Sejarah terus diajar di peringkat sekolah menengah sebagai mata pelajaran aliran kemanusiaan. Mulai tahun 1992, Sejarah dijadikan satu daripada mata pelajaran teras (dari Tingkatan Satu hingga Tingkatan Lima). Kurikulum Sejarah, di peringkat Sekolah Menengah Rendah (SMR) mempunyai kesinambungan dengan kurikulum Sejarah di peringkat Sekolah Menengah Atas (SMA). Pada tahun 1992, Sejarah Peradaban Dunia diperkenalkan dalam kurikulum Sejarah untuk pelajar-pelajar Tingkatan Empat. Tujuannya ialah untuk mengimbang isi kandungan mata pelajaran Sejarah. Selain itu, pelajar-pelajar dapat melihat sejarah tanah air daripada kaca mata budaya negara sendiri, kaca mata budaya Barat dan kaca mata budaya Timur. Rasional mempelajari Sejarah Peradaban Dunia ialah supaya pelajar tidak menjadi seperti 'katak di bawah tempurung' (Subadrah Nair \& Malar, 1992).

Kejayaan guru sejarah menyampaikan mesej sejarah sebagai suatu nilai moral yang perlu difahami pelajar, terletak pada bagaimana cara guru mengembangkan kaedah pengajaran di dalam kelas. Penggunaan kaedah pengajaran yang tepat dan digabungkan dengan cara yang kreatif akan membolehkan mesej sejarah dapat disampaikan kepada pelajar (Anwar Senen \& Imam Barnadib, 2000).

Sejajar dengan perkembangan dunia dalam bidang teknologi maklumat dan komunikasi, pendidikan dilihat sebagai aspek antara yang terkesan hasil dari gelombang globalisasi ini dan rentetan dari penggunaan kaedah pembelajaran jarak jauh dan e-pembelajaran, dunia pendidikan cuba untuk meneroka dimensi pembelajaran bagi pengguna yang menginginkan pembelajaran setiap masa dan dimana-mana. Lalu, lahirlah istilah kaedah pembelajaran secara mudah alih atau dipanggil dengan pembelajaran mobile (M-Learning) (Aliff Nawi dan Mohd Isa Hamzah, 2013 / Brown, 2005 / Keegan, 2005). Oleh itu, pembelajaran sejarah di abad ke-21 ini akan menjadi lebih menarik melalui aplikasi teknologi terkini seperti web atau sistem aplikasi mobile. Ini adalah kerana setiap kandungan 
sejarah dapat diringkaskan dalam bentuk grafik yang menarik melalui medium yang dikenali sebagai infografik dan disebarkan secara digital melalui platform teknologi digital abad ini iaitu teknologi aplikasi mobile bagi memudahkan pelajar untuk belajar dengan lebih berkesan.

\subsection{Isu Dalam Pembelajaran Subjek Sejarah}

Pengetahuan pelajar kebanyakannya berpusat kepada guru-guru di sekolah yang mana kebanyakan guru akan menyampaikan segala bahan mengajar berdasarkan kandungan bahan pembelajaran. Menurut Mizan Kamalina Assin (2013), Kaedah pengajaran berpusatkan guru masih banyak diamalkan dan kebanyakan guru biasanya menyampaikan pengetahuan berdasarkan isi kandungan dan berpusatkan pengajaran itu sendiri. Beliau juga menyatakan matlamat kebanyakan guru hanyalah ke arah menyediakan pelajar untuk menghadapi peperiksaan pada setiap hujung tahun. Apa yang terjadi adalah proses pembelajaran yang berlaku secara dasarnya sahaja, tidak mementingkan kefahaman pelajar sama ada pelajar benar-benar menguasai kemahiran yang dipelajari ataupun tidak.

Hal ini selari dengan kenyataan Ahmad dan Harun (2004) yang menyatakan bahawa ada kalanya setiap konsep yang disampaikan kurang jelas dan berada jauh di luar konteks sebenar. Hasilnya pelajar tidak memahami apa yang dipelajari dan ini akan memberi kesan ke atas sikap, minat dan pencapaian pelajar terhadap mata pelajaran tersebut. Y.R Subakti (2010) menyatakan bahawa masih ramai guru berpegang pada paradigma konvensional iaitu paradigma 'guru menjelaskan dan murid mendengar '. Kaedah pembelajaran sejarah seperti ini telah menjadikan pelajaran sejarah membosankan.

Menurut Anwar Senen dan Imam Barnadib (2000), Penekanan pada mesej sejarah adalah penting, kerana selama ini masih terkesan bahawa mata pelajaran sejarah hanya dianggap sebagai pengetahuan hafalan sejumlah peristiwa masa lalu. Hal demikian menyebabkan pemahaman pelajar terhadap pelajaran sejarah hanya terbatas pada pengetahuan deskriptif konsep apa, di mana, bila dan mengapa suatu peristiwa sejarah berlaku dan subjek sejarah sebagai mata pelajaran di sekolah dalam konsep pendidikan masih jauh ketinggalan dari segi kaedah pengajaran. Prof. Rahimah $\mathrm{Hj}$. Ahmad menyatakan bahawa wawasan pendidikan sejarah tidak akan dapat direalisasikan jika corak pengajaran matapelajaran sejarah disekolah masih bersifat tradisional dan membosankan murid. Hakikat ini perlu disedari supaya sentiasa bersedia melakukan perubahan untuk menjadikan pengajaran dan pembelajaran sejarah lebih berkesan (Ahmad Ali Seman, 2009). 
3.0 Pembangunan Instrumen Dalam Menilai Tahap Penerimaan Terhadap Pengajaran Menggunakan Aplikasi Mobile

Instrumen pengumpulan data yang digunakan adalah soalan soal selidik. la terdiri dari skala lima mata. Tahap penerimaan adalah berdasarkan konstrak mengikut kesesuaian terhadap soalan berkaitan pendidikan dan persepsi guru. Jadual 1 dibawah adalah menunjukkan pecahan tiga konstrak soalan penerimaan terhadap penggunaan aplikasi mobile dalam pengajaran subjek sejarah.

Jadual 1: Pecahan konstrak soalan penerimaan

\begin{tabular}{lll}
\hline Soalan & \multicolumn{1}{c}{ Konstrak Soalan } \\
\hline \multirow{2}{*}{ Penerimaan } & 1. & Kebergunaan \\
& 2. & Kesenangan Untuk Difahami \\
& 3. & Keseronokan Mengajar \\
\hline
\end{tabular}

Instrumen yang dibangunkan adalah hasil rujukan daripada Skala Likert yang mana melibatkan skor pecahan kepada nombor satu hingga lima untuk setiap pilihan yang dibuat oleh responden bagi menilai sejauhmana responden menyokong kenyataan item soal selidik (Johari Hassan dan Juwairiah Arifin, 2011). Jadual 2 menunjukkan skor skala Likert adalah seperti yang ditunjukkan dibawah.

Jadual 2: Skor skala Likert

\begin{tabular}{|l|c|c|c|c|c|}
\hline \multirow{2}{*}{ Skor } & \multicolumn{3}{|c|}{ Tidak bersetuju } & \multicolumn{2}{c|}{ Bersetuju } \\
\cline { 2 - 6 } & $\mathbf{1}$ & $\mathbf{2}$ & $\mathbf{3}$ & $\mathbf{4}$ & $\mathbf{5}$ \\
\hline \multirow{2}{*}{$\begin{array}{c}\text { Sangat tidak } \\
\text { setuju }\end{array}$} & Tidak setuju & $\begin{array}{c}\text { Kurang } \\
\text { setuju }\end{array}$ & Setuju & Sangat setuju \\
\hline
\end{tabular}

\subsection{Kesahan Instrumen}

Instrumen yang dihasilkan telah disahkan melalui kajian rintis (Pilot test) dengan kebolehpercayaan daripada responden seramai 30 orang yang terdiri daripada guru-guru sejarah dan pensyarah teknologi kreatif. Segala kritikan dan pendapat berkaitan soalan soal selidik telah diambil sebagai penambahbaikan terhadap soalan yang akan dihasilkan sebelum diserahkan kepada responden yang dipilih. Soalan tahap penerimaan telah menunjukkan nilai 


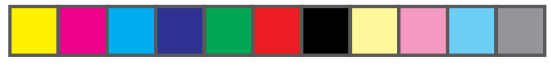

Alfa Cronbach melebihi 0.7 dan keseluruhan nilai Alpha Cronbach bagi setiap konstrak juga menunjukkan nilai melebihi 0.7 , manakala soalan dalam bahagian demografi tidak dihitung kesahan instrumennya kerana bahagian demografi merupakan soalan yang berkaitan pengenalan kepada responden. Segala kesahan kajian rintis berdasarkan Alpha Cronbach dibuat menggunakan perisian SPSS (Statistical Package for the Social Science). Menurut Hair, Black, Babin, Anderson dan Tatham (2006), nilai Alpha Cronbach yang melebihi nilai 0.7 adalah nilai kesahan yang baik dan dapat diterima dalam mengukur sesebuah instrumen (Siti Zuraida Abdul Manaf, Ahmad Syukri Mohamad Zaid, Rosseni Din, Analisa Hamdan, Nor Syazwani Mat Salleh, Intan Farahana Kamsin, Aidah Abdul Karim, dan Maimun Aqsya Lubis, 2015). Kenyataan ini juga disokong oleh George dan Mallery (2003), yang menyatakan kesahan nilai Alpha Cronbach melebihi 0.60 atau 0.70 ke atas adalah nilai kesahan instrumen yang boleh diterima (Megha Budruk dan Sonja A. Wilhelm Stanis, 2013). Dapatan (Jadual 3) menunjukkan kesahan Instrumen soal selidik bagi soalan penerimaan.

Jadual 3: Kesahan Instrumen

\begin{tabular}{ccc}
\hline Soalan & Nilai Alpha Cronbach & Item \\
\hline Penerimaan & 0.97 & 16 Soalan \\
\hline
\end{tabular}

\subsection{Penerimaan Guru Terhadap Aplikasi Mobile Dalam Pengajaran}

Dalam kajian yang dibuat, kajian untuk melihat penerimaan guru terhadap penggunaan aplikasi mobile dalam pengajaran matapelajaran sejarah diberi penekanan. Soalan soal selidik bagi melihat penerimaan guru terhadap penggunaan aplikasi mobile telah dibuat. Soalan-soalan berkaitan dengan penerimaan disertakan dibahagian soalan penerimaan. terdapat lima pilihan untuk menyatakan kecenderungan terhadap penerimaan guru terhadap penggunaan medium aplikasi mobile dalam sesi pengajaran subjek sejarah iaitu 1 adalah sangat tidak setuju, 2 tidak setuju, 3 tidak pasti, 4 setuju dan 5 sangat setuju. Bahagian soalan untuk melihat penerimaan guru dipecahkan kepada tiga konstrak iaitu kebergunaan, kesenangan untuk difahami dan keseronokan mengajar. Nilai min akan dianalisis pada setiap konstruk. Bagi melihat tahap penerimaan guru, analisis keseluruhan konstruk pula dibuat untuk melihat sama ada guru bersetuju ataupun menolak kaedah pengajaran menggunakan medium yang baru. Jadual 4 di bawah menunjukkan hasil analisis melalui soalan soal selidik penerimaan guru terhadap pengajaran menggunakan kaedah m-pembelajaran. 
Jadual 4: Hasil analisis penerimaan guru

\begin{tabular}{|l|c|c|c|c|}
\hline Item & $\mathbf{N}$ & Minimun & Maksimum & Min \\
\hline Kebergunaan & 150 & 2.50 & 5.00 & 4.17 \\
\hline Kesenangan untuk difahami & 150 & 2.75 & 5.00 & 4.05 \\
\hline Keseronokan mengajar & 150 & 2.00 & 5.00 & 4.41 \\
\hline
\end{tabular}

Dapatan analisis menunjukkan nilai min bagi ketiga-tiga konstrak pecahan soalan adalah tinggi (menunjukkan angka melebihi nilai Min 4.0). Ini menunjukkan bahawa tahap penerimaan guru terhadap penggunaan aplikasi dalam pengajaran diterima baik.

\subsection{Pecahan Konstrak Soalan Penerimaan}

\begin{tabular}{|c|c|c|c|c|c|c|}
\hline Bil & Kebergunaan & 1 & 2 & 3 & 4 & 5 \\
\hline 1 & $\begin{array}{l}\text { Aplikasi mobile sangat berguna, terutama apabila hendak melihat } \\
\text { kandungan pengajaran secara sepintas lalu sebelum sesi pengajaran } \\
\text { bermula }\end{array}$ & & & & & \\
\hline 2 & $\begin{array}{l}\text { Pengajaran dalam bentuk digital sangat berguna kepada pelajar } \\
\text { untuk keperluan pembelajaran }\end{array}$ & & & & & \\
\hline 3 & $\begin{array}{l}\text { Pembelajaran dalam bentuk digital sangat berguna kepada guru } \\
\text { untuk keperluan pengajaran }\end{array}$ & & & & & \\
\hline Bil & Kesenangan Untuk Di Fahami & 1 & 2 & 3 & 4 & 5 \\
\hline 4 & $\begin{array}{l}\text { Aplikasi mobile boleh memaparkan maklumat yang mudah difahami } \\
\text { oleh pelajar. }\end{array}$ & & & & & \\
\hline 5 & $\begin{array}{l}\text { Penggunaan visual, illustrasi dan teks menarik minat pelajar untuk } \\
\text { terus belajar. }\end{array}$ & & & & & \\
\hline 6 & $\begin{array}{l}\text { Penggunaan visual, illustrasi dan teks yang bersesuaian } \\
\text { menyenangkan para pelajar untuk memahami kandungan yang } \\
\text { hendak disampaikan. }\end{array}$ & & & & & \\
\hline 7 & $\begin{array}{l}\text { Olahan visual, illustrasi, teks dan konsep yang menarik mampu } \\
\text { memudahkan pelajar untuk memahami maklumat yang hendak } \\
\text { disampaikan. }\end{array}$ & & & & & \\
\hline
\end{tabular}




\begin{tabular}{|c|c|c|c|c|c|c|}
\hline Bil & Keseronokan Mengajar & 1 & 2 & 3 & 4 & 5 \\
\hline 8 & $\begin{array}{l}\text { Saya rasa sangat seronok untuk mengajar dengan menggunakan } \\
\text { medium penyampaian yang baru. }\end{array}$ & & & & & \\
\hline 9 & $\begin{array}{l}\text { Kandungan fakta sejarah yang mudah, menyeronokkan saya untuk } \\
\text { terus mengajar. }\end{array}$ & & & & & \\
\hline 10 & $\begin{array}{l}\text { Saya rasa, aplikasi mobile membantu untuk mengurangkan bebanan } \\
\text { kerja saya sebagai seorang guru }\end{array}$ & & & & & \\
\hline 11 & $\begin{array}{l}\text { Saya akan teruja apabila menggunakan aplikasi mobile semasa } \\
\text { mengajar. }\end{array}$ & & & & & \\
\hline
\end{tabular}

\subsection{Kesimpulan}

Kesimpulannya, kajian ini adalah lebih memfokuskan untuk menilai tahap penerimaan guru yang mengajar subjek sejarah dalam penggunaan kaedah baru iaitu menggunakan aplikasi mobile dalam pengajaran. Dapatan kajian terhadap penerimaan guru-guru sejarah adalah sangat penting kerana ia adalah asas kepada permulaan kajian secara berterusan. Kajian lanjutan berkaitan pembangunan aplikasi mobile adalah diperlukan pada masa akan datang kerana dapatan kajian telah menunjukkan guru-guru sejarah sangat memerlukan dan menerima kaedah pengajaran menggunakan aplikasi mobile dengan baik dan sebagai bahan bantu mengajar didalam kelas sebagai medium penyampaian maklumat pengajaran kepada pelajar.

\section{Rujukan}

Aziz, Z., \& Jair, N. (2009). Penggunaan Peta Konsep untuk Meningkatkan Pencapaian Mata Pelajaran Sejarah bagi Pelajar Tingkatan Dua (The Use of Concept Maps in Improving Achievement in The Subject of History for Form Two Students). JURNAL PENDIDIKAN MALAYSIA (Malaysian Journal of Education), 34(1), 3-15.

Nair, S. (2005). Penggunaan model konstruktivisme lima fasa needham dalam pembelajaran sejarah. Malaysian Journal of Educators and Education, 20, 21-41.

Senen, A., \& Barnadib, I. (2000). Tantangan guru sejarah: pesan sejarah sebagai konsep pendidikan nilai. Jurnal Penelitian dan Evaluasi Pendidikan, 2(3).

Nawi, A., \& Hamzah, M. I. (2013). Tahap penerimaan penggunaan telefon bimbit sebagai M-Pembelajaran dalam Pendidikan Islam. Journal of Islamic and Arabic Education, 5(1), 1-10. 


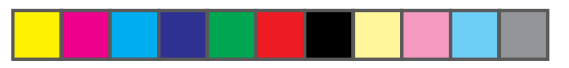

Assin, M. K. (2013). Amalan penggunaan modul pengajaran berasaskan Modul Multimedia Interaktif (MMI) dalam Pendidikan Teknik dan Vokasional (PTV) (Doctoral dissertation, Universiti Tun Hussein Onn Malaysia).

Subakti, Y. R. (2010). Paradigma Pembelajaran Sejarah Berbasis Konstruktivisme. Jurnal SPPS, 24(1), 31-53.

Arifin, J. (2008). Pembinaan instrumen penilaian untuk menilai perisian cd-rom interaktif (CDRI) matapelajaran Fizik sekolah menengah kebangsaan (Doctoral dissertation, Universiti Teknologi Malaysia).

Budruk, M., \& Stanis, S. A. W. (2013). Place attachment and recreation experience preference: A further exploration of the relationship. Journal of Outdoor Recreation and Tourism, 1, 51-61.

Gliem, J. A., \& Gliem, R. R. (2003). Calculating, interpreting, and reporting Cronbach's alpha reliability coefficient for Likert-type scales. Midwest Research-to-Practice Conference in Adult, Continuing, and Community Education.

Seman, A. A. B. (2014). Pemupukan Patriotisme Melalui Pendidikan Multikultural Dalam Pendidikan Sejarah di Malaysia: Satu Tinjuan Perspektif. LENTERA (Jurnal IImu-IImu Sejarah, Budaya Dan Sosial), 1(02), 28-49.

Manaf, A., Zuraida, S., Zaid, A. S. M., Din, R., Hamdan, A., Salleh, N. S. M.,\& Lubis, M. A. (2015). Aplikasi Mudah Alih Panduan Solat dan Penggunaannya= The User Guide of the Mobile Muslim Prayer Application. 'Ulūm Islāmiyyah Journal, 197(3537), 1-16. 